ARTICLE

Clinical Study

\title{
Predictive factors for early progression during induction chemotherapy and chemotherapy-free interval: analysis from PRODIGE 9 trial
}

Thomas Aparicio', Jaafar Bennouna ${ }^{2}$, Karine Le Malicot ${ }^{3}$, Valérie Boige ${ }^{4}$, Julien Taieb ${ }^{5}$, Olivier Bouché ${ }^{6}$, Jean-Marc Phelip ${ }^{7}$, Eric François ${ }^{8}$, Christian Borel $^{9}$, Roger Faroux ${ }^{10}$, Laetitia Dahan ${ }^{11}$, Jean-Baptiste Bachet ${ }^{12}$, Joelle Egreteau ${ }^{13}$, Marie-Christine Kaminsky ${ }^{14}$, Jean-Marc Gornet ${ }^{1}$, Oana Cojocarasu ${ }^{15}$, Mohamed Gasmi ${ }^{16}$, Véronique Guerin-Meyer ${ }^{17}$, Côme Lepage ${ }^{18}$, François Ghiringhelli ${ }^{19}$ and for PRODIGE investigators/collaborators ${ }^{9}$

BACKGROUND: Identifying patients with metastatic colorectal cancer who will have an early disease progression during induction chemotherapy (IC) and identifying patients who may have a chemotherapy-free interval (CFI) after IC are two major challenges. METHODS: A logistic model was used to identify factors associated with early progression during IC and with short duration of the first CFI in 488 patients enrolled in the PRODIGE 9 trial. Independent factors were defined with a threshold 0.10 .

RESULTS: In multivariate analysis, baseline leukocytes $>10 \times 10^{9} / \mathrm{L}(\mathrm{OR}=1.98[1.02-3.8], p=0.04)$, and stable or increasing CEA at 2 months $(\mathrm{OR}=3.61$ [1.68-7.75], $p=0.01$ ) were independent factors associated with progression during IC. Male gender $(\mathrm{OR}=1.725$ $[0.92-3.325], p=0.09)$ and no tumour response at first evaluation $(\mathrm{OR}=1.90[0.96-3.76], p=0.07)$ were significantly associated with a short CFI. The presence of BRAF V600E mutation was also associated with short CFI (OR=4.59 [0.95; 22.3], $p=0.058$ ).

CONCLUSION: High baseline leukocyte count and the lack of CEA decrease level at first evaluation were associated with early progression, and could be in favour of early chemotherapy intensification. Male gender, no tumour response at first evaluation and $B R A F$ mutation are associated with a short CFI, and may be considered for maintenance chemotherapy after IC.

CLINICAL TRIAL NUMBER: NCT00952029.

British Journal of Cancer (2020) 122:957-962; https://doi.org/10.1038/s41416-020-0735-8

\section{BACKGROUND}

The prognosis of patients with metastatic colorectal cancer (mCRC) has been significantly improved by the use of several consecutive chemotherapy drugs. ${ }^{1}$ First-line chemotherapy irinotecan, 5-fluorouracil (5FU) and bevacizumab became a standard of care in $\mathrm{mCRC}^{2,3}$ Due to the prolonged survival, up to 2-3 years under treatment, and in order to avoid heavy treatment burden and toxicity, chemotherapy-free intervals (CFI) were proposed in different studies with oxaliplatin- or irinotecan-based first-line induction chemotherapy (IC). ${ }^{4-6}$

A pooled analysis of several trials has shown that CFI did not impair overall survival (OS) and advocate for biomarker research to define a predictive factor. ${ }^{7}$ Nevertheless, the predictive factors associated with a long duration of CFI remain poorly studied. On the other hand, early identification of patients who will have an early progression during IC is an important challenge in order to intensify front-line treatment. Previous recent large trials have reported prognostic factors for progression-free survival (PFS), ${ }^{8-10}$ but not for early progression within the first 6 months of treatment. Moreover, two of these trials evaluated front-line treatment in the subgroup of patients with wild-type RAS mCRC., The randomised phase 3, PRODIGE 9 study, aimed to assess the tumour control duration with bevacizumab maintenance or observation after irinotecan-based IC combined with bevacizumab. ${ }^{11}$ Two other recent trials randomised

\footnotetext{
${ }^{1}$ Gastroenterology and Digestive Oncology Department, Hôpital Saint Louis, APHP.Nord, Université de Paris, Paris, France; ${ }^{2}$ Gastroenterology and Digestive Oncology Department, IMAD, Nantes University Hospital, Nantes, France; ${ }^{3}$ Fédération Francophone de Cancérologie Digestive (FFCD); Statistics Department, EPICAD INSERM LNC-UMR 1231, Université de Bourgogne et Franche Comté, Dijon, France; ${ }^{4}$ Medical Oncology Department, Gustave Roussy, Villejuif, France; ${ }^{5}$ Hepato-Gastroenterology and GI Oncology Department, Hôpital Européen Georges Pompidou, APHP, Université de Paris, Paris, France; ${ }^{6}$ Hepato-Gastroenterology Department, University Hospital Robert Debré, Reims,

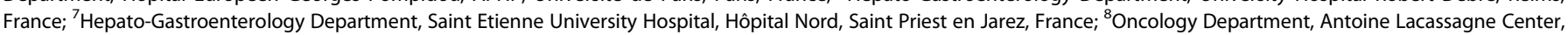

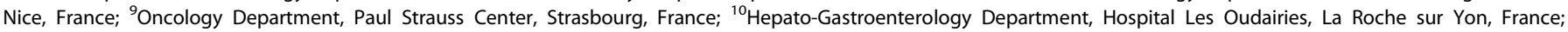
${ }^{11}$ Hepato-Gastroenterology and Oncology Department, University Hospital la Timone, Marseille, France; ${ }^{12}$ Hepato-Gastroenterology Department, Hôpital Pitié-Salpêtrière, APHP, Sorbonne Université, Paris, France; ${ }^{13}$ Radiotherapy and Oncology Department, Centre Hospitalier Bretagne Sud, Lorient, France; ${ }^{14}$ Oncology Department, Institut de Cancérologie de Lorraine, Vandoeuvre-lès-Nancy, France; ${ }^{15}$ Onco-Hematology Department, Centre hospitalier du Mans, Le Mans, France; ${ }^{16}$ Hepato-Gastroenterology Department, Hôpital Nord,

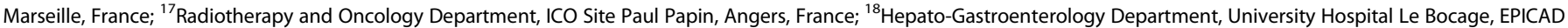
INSERM LNC-UMR 1231, Université de Bourgogne et Franche Comté, Dijon, France and ${ }^{19}$ Oncology Department, Centre Georges-François Leclerc, Dijon, France Correspondence: Thomas Aparicio (thomas.aparicio@aphp.fr)

Previous presentation: This work was presented at the annual meeting of ESMO in 2017 and JFHODs 2019 (references in the Acknowledgment section). Please see the Supplementary Appendix for a list of the PRODIGE 9 Investigators/Collaborators.
}

Received: 13 September 2019 Revised: 26 December 2019 Accepted: 17 January 2020

Published online: 4 February 2020 
patients without progression after IC. ${ }^{12,13}$ As the randomisation was performed prior to the front-line treatment whatever the RAS status, analysis of the PRODIGE 9 trial allows the determination of prognostic factors in all patients with $\mathrm{mCRC}$.

The purpose of this ancillary study of the PRODIGE 9 trial is to determine the prognostic factors for early progression during IC, and during the first CFI in the subgroup of patients without progression of the disease after IC.

\section{METHODS}

PRODIGE 9 was an open-label, randomised, multicentre, phase 3 study conducted by the Fédération Francophone de Cancérologie Digestive (FFCD) and the PRODIGE intergroup in 66 French centres comparing IC with FOLFIRI plus bevacizumab followed by bevacizumab monotherapy (maintenance arm) or the same induction treatment followed by observation. ${ }^{11}$ The IC was planned for 12 cycles ( 6 months) after randomisation. The main eligible criteria were histologically proven, non-resectable $m C R C$, WHO status $\leq 2$, life expectancy $\geq 3$ months, absence of previous chemotherapy or anti-angiogenic therapy for metastatic disease. The primary endpoint was the tumour control duration defined as the time elapsed between randomisation and tumour progression during a chemotherapy sequence. There were no significant differences between the two arms not only for the primary endpoint but also for the median duration of the first CFI. ${ }^{14}$

Progression or death during IC was considered as the event for prognostic factor analysis of early progression during IC. Only patients without progression during induction chemotherapy who have entered in the CFI phase were analysed for the determination of prognostic factors related to the duration of the first CFI. Duration of the first CFI was defined as the time between the end of IC and the first reintroduction of chemotherapy whatever the regimen or death.

The following factors were evaluated for early progression during IC, and for early ( $<3$ months) or late progression (>5 months) during the first CFI: treatment arm, sex, age, WHO performance status (PS), resection of primary tumour, number of metastatic sites, primary localisation, leukocytes, platelets, alkaline phosphatase, carcinoembryonic antigen (CEA) level, tumour KRAS status, tumour BRAF status (tumour with KRAS mutation was considered as BRAF wild type) and decrease in CEA $>50 \%$ at 2 months. Tumour response at the end of induction chemotherapy and early shrinkage at first evaluation were evaluated only for CFI duration. A logistic model was used to identify the prognostic factors. A significance level of 0.2 was required to enter into the final univariate model and to stay in the multivariate model. We have considered as interesting a factor with a level of 0.10 in the multivariate model.

\section{RESULTS}

Between March 2010 and July 2013, the PRODIGE 9 trial enrolled 494 patients. Among them, six patients withdrew their consent (3) or were never treated (3); thus, the modified intent-to-treat population was 488 patients randomly assigned to either FOLFIRI plus bevacizumab IC followed by bevacizumab maintenance $(n=245)$, or to the same IC followed by observation during CFI $(n=243)$.

Disease progression or death during IC occurred in 85 (17.4\%) patients. Among the 403 patients who have no progression or death during IC, 59 had no CFI due to investigator decision, toxicities or other reasons. Among the remaining 344 patients, 128 (37.2\%) patients had a CFI <3 months, $100(29 \%)$ patients had a CFI between 3 and 5 months and 116 (33.7\%) patients had a CFI $>5$ months (Fig. 1).

Factors associated with progression during induction chemotherapy

Baseline characteristics of patients with and without tumour progression during IC are presented in Supplementary Table S1. Univariate analysis revealed that baseline WHO performance status of 2 , baseline leukocytes $>10 \times 10^{9} / \mathrm{L}$, baseline CEA upper limit of normal and stable or increasing CEA at 2 months after the beginning of IC were associated with a higher risk of progression during IC (Table 1). In multivariate analysis, baseline leukocytes $>10 \times 10^{9} / \mathrm{L}$ and stable or increasing CEA at 2 months were independent factors associated with progression during IC (Table 2). The ratio of neutrophils/leukocytes was also explored, but adds no additional result to the leukocyte count alone (data not shown).

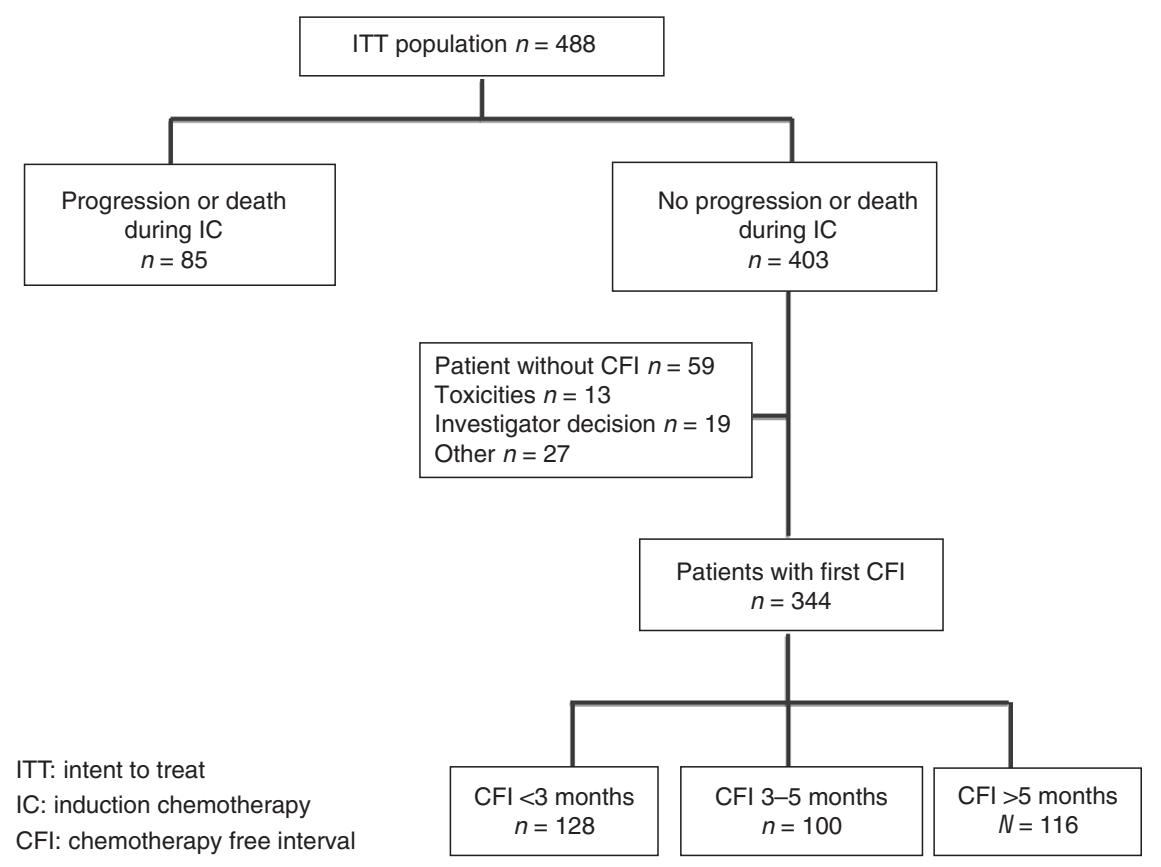

Fig. 1 Flowchart. 
Table 1. Univariate analysis of characteristics associated with a progression during induction chemotherapy.

\begin{tabular}{|c|c|c|c|}
\hline \multicolumn{2}{|l|}{ Characteristics } & $\begin{array}{l}\text { OR for progression } \\
1.28\end{array}$ & $\begin{array}{l}{[95 \% \mathrm{Cl}], p \text { value }} \\
{[0.79-2.07], p=0.31}\end{array}$ \\
\hline Age & $\leq 65$ vs $>65$ & 1.16 & {$[0.73-1.86], p=0.52$} \\
\hline Primary tumour resected & No vs yes & 1.26 & {$[0.79-2.02], p=0.33$} \\
\hline Number of metastatic sites & $>1$ vs 1 & 1.16 & {$[0.71-1.88], p=0.55$} \\
\hline Baseline leukocytes & $>10 \times 10^{9} / \mathrm{L}$ vs $\leq 10 \times 10^{9} / \mathrm{L}$ & 1.91 & {$[1.16-3.15], p=0.01$} \\
\hline Baseline platelet & $\geq 400 \times 10^{9} / \mathrm{L}$ vs $<400 \times 10^{9} / \mathrm{L}$ & 1.68 & {$[0.92-3.08], p=0.09$} \\
\hline Baseline alkaline phosphatase & $>300$ vs $\leq 300 \mathrm{U} / \mathrm{L}$ & 1.39 & {$[0.79-2.44], p=0.25$} \\
\hline Baseline CEA & $>$ ULN vs normal & 2.46 & {$[0.86-7.09], p=0.10$} \\
\hline Two months CEA vs baseline CEA & Stable or increase vs decrease $>50 \%$ & 3.00 & {$[1.44-6.23], p=0.01$} \\
\hline
\end{tabular}

Table 2. Multivariate analysis of characteristics associated with a progression during induction chemotherapy.

\begin{tabular}{llll}
\hline Characteristics & $N=363$ & OR for progression & {$[95 \% \mathrm{Cl}, p$ value } \\
\hline WHO performance status & 1 vs 0 & 1.18 & 1.65 \\
Baseline leukocytes & 2 vs 0 & 1.98 & {$[0.61-2.27], p=0.80$} \\
Baseline CEA & $>10 \times 10^{9} / \mathrm{L}$ vs $\leq 10 \times 10^{9} / \mathrm{L}$ & 2.84 & {$[0.57-4.75], p=0.40$} \\
Two months CEA vs baseline CEA & $>$ ULN vs normal & 3.61 & {$[1.02-3.8], p=0.04$} \\
Baseline platelet & Stable or increase vs decrease $>50 \%$ & 1.09 & {$[0.93-8.70], p=0.07$} \\
\hline CEA carcinoembryonic antigen, ULN upper limit of normal. & $\geq 400 \times 10^{9} / \mathrm{L}$ vs $<400 \times 10^{9} / \mathrm{L}$ & {$[0.55-2.14], p=0.81$} \\
\hline
\end{tabular}

Factors associated with short duration of chemotherapy-free interval

Baseline characteristics of patients according to the CFI duration are presented in Supplementary Table S2. Univariate analysis revealed that male gender, WHO performance status of 1 or 2 , unresected primary tumour, right colon primary, baseline leukocytes $>10 \times 10^{9} / \mathrm{L}$, baseline platelet $>400 \times 10^{9} / \mathrm{L}$, baseline alkaline phosphatase $>300 \mathrm{IU} / \mathrm{L}$, baseline CEA upper limit of normal, BRAF mutation and no tumour response at 2 months were associated with a short duration of CFI (Table 3 ). In multivariate analysis, male gender and no tumour response at 2 months were associated with a short CFI (Table 4). The multivariate analysis performed in the subgroup of patients with BRAF V600E mutation status available revealed that $B R A F$ - mutated status was the only factor associated with a short CFI (OR $=4.59[0.95 ; 22.26], p=0.058)$.

\section{DISCUSSION}

Our results showed that baseline-elevated leukocytes and stable or increasing CEA at 2 months were independent factors associated with progression during IC. In this study, we have investigated prognostic factors for early progression within the first 6 months of chemotherapy. In the PRODIGE 9 trial, the independent prognostic factors associated with a shorter PFS were PS 2 and BRAF mutation. ${ }^{14}$ BRAF mutation was also reported as a prognostic factor for shorter PFS in previous trials ${ }^{10,15}$ after both doublet and triplet chemotherapy combined with bevacizumab. Nevertheless, the BRAF mutation was not found as a prognostic factor of early progression in our study. Baseline CEA and early CEA variation during chemotherapy were already reported as associated with PFS or OS. ${ }^{16,17}$ Interestingly, the prognostic value of baseline CEA was reported in patients treated with FOLFIRI plus bevacizumab, but not with FOLFIRI plus cetuximab. ${ }^{18}$ In this study, the lack of decrease in CEA at 2 months was associated with an early progression, and potentially should be considered in order to intensify chemotherapy. Circulating DNA is described as another early marker of chemotherapy efficacy. ${ }^{19}$ Unfortunately, this biomarker was not collected in our study. CEA and circulating DNA monitoring have both advantages and limitations. CEA is easy to perform with low cost, but some tumours do not produce even CEA, and could not be evaluated with this marker. Circulating DNA requires specific technology, provides additional cost and needs further evaluation in a metastatic setting. It would be worthwhile to compare the predictive value of both markers. Elevated baseline leukocytes are prognostic of an early progression in this study. The Köhne criteria include this parameter as a prognostic factor for OS. ${ }^{20}$ However, elevated baseline leukocytes were not a prognostic factor for PFS on the main analysis of PRODIGE 9 trial. $^{14}$ Thus, according to our results, both parameters, the lack of the CEA decrease level and the elevated baseline leukocytes as prognostic factors for early progression, should be confirmed in another series. Other prognostic factors for early progression could also be integrated as radiomic evaluation ${ }^{21}$ or biological markers beyond $B R A F$ mutation as consensual molecular classification. ${ }^{22}$

Male gender and no tumour response at 2 months according to RECIST 1.1 criteria were found to be prognostic for a short first CFI. Previous studies have assessed prognostic factors for CFI or 
Predictive factors for early progression during induction chemotherapy...

T Aparicio et al.

Table 3. Univariate analysis of characteristics associated with a short duration $(<3$ months) of chemotherapy-free interval.

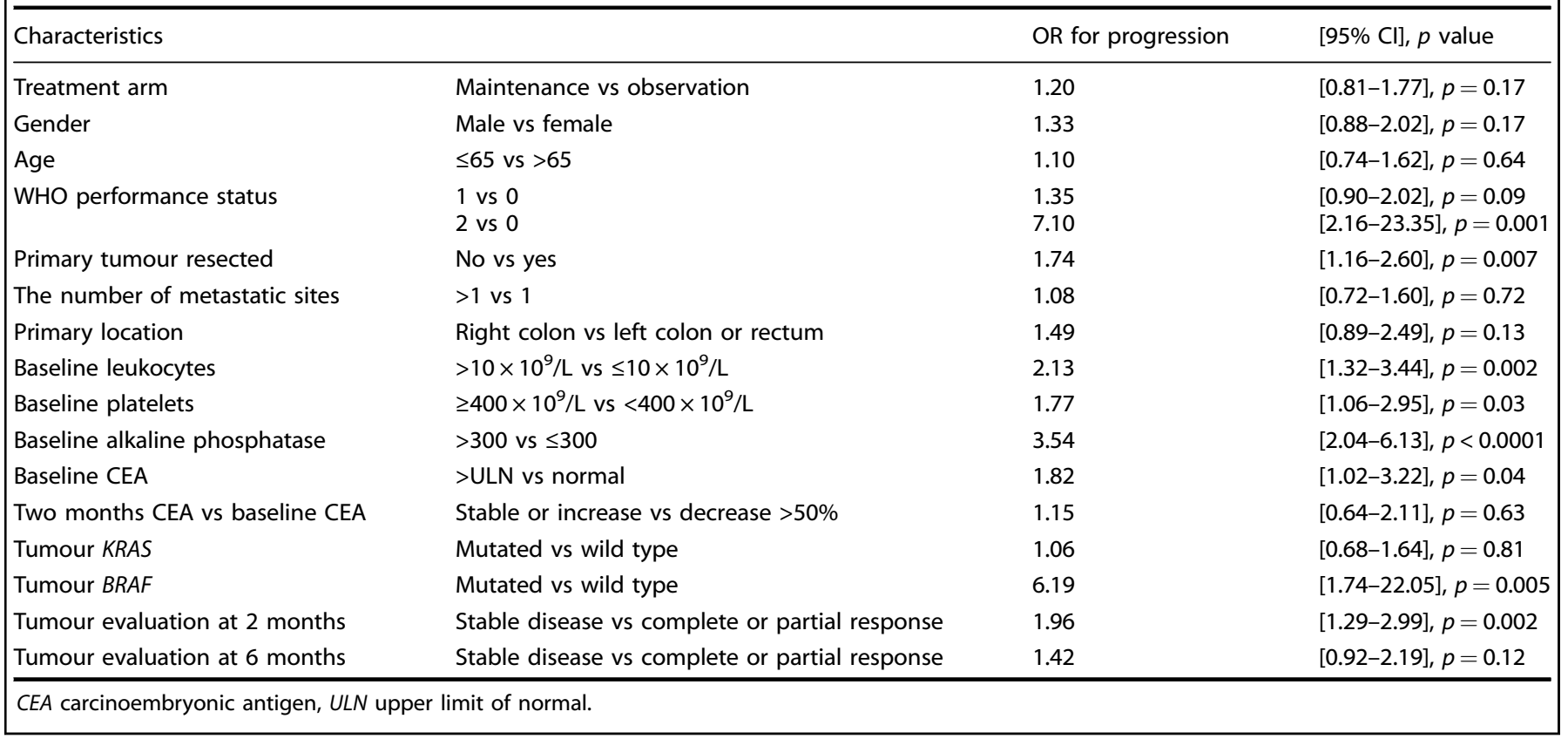

Table 4. Multivariate analysis of characteristics associated with a short duration ( $<3$ months) of chemotherapy-free interval.

\begin{tabular}{llll}
\hline Characteristics & $N=172$ & OR for progression & {$[95 \% \mathrm{Cl}, p$ value } \\
\hline Gender & Male vs female & 1.72 & 1.33 \\
WHO performance status & 1 vs 0 & 3.38 & 1.57 \\
Primary tumour resected & 2 vs 0 & 1.35 & {$[0.72-2.44], p=0.36$} \\
Primary location & No vs yes & 0.95 & {$[0.48-23.78], p=0.22$} \\
Baseline leukocytes & Right colon vs left colon or rectum & 1.35 & {$[0.84-2.98], p=0.16$} \\
Baseline alkaline phosphatase & $>10 \times 10^{9} / \mathrm{L}$ vs $\leq 10 \times 10^{9} / \mathrm{L}$ & 1.94 & {$[0.70-2.62], p=0.37$} \\
Baseline CEA & $>300$ vs $\leq 300 \mathrm{U} / \mathrm{L}$ & 1.32 & {$[0.43-2.08], p=0.89$} \\
Baseline platelet & $>\mathrm{ULN}$ vs normal & 1.90 & {$[0.54-3.37], p=0.53$} \\
Tumour evaluation at 2 months & $\geq 400 \times 10^{9} / \mathrm{L}$ vs $<400 \times 10^{9} / \mathrm{L}$ & {$[0.80-4.71], p=0.14$} \\
Tumour evaluation at 6 months & Stable disease vs complete or partial response & {$[0.59-2.96], p=0.50$} \\
\hline CEA carcinoembryonic antigen, ULN upper limit of normal. & Stable disease vs complete or partial response & {$[0.96-3.76], p=0.07$} \\
{$[0.69-2.56], p=0.39$} \\
\hline
\end{tabular}

maintenance treatment. In the COIN trial that evaluated IC continuation compared with $\mathrm{CFI}$, baseline thrombocytosis was associated with a short $\mathrm{CFI}^{23}$ In our study, baseline thrombocytosis was associated with short CFI in univariate analysis but not in multivariate analysis, suggesting confounding factors or a lack of statistical power. In the CAIRO 3 trial, tumour response and synchronous metastasis were associated with a longer PFS in the maintenance arm with capecitabine plus bevacizumab. ${ }^{12}$ Patients with stable disease at the first evaluation have a shorter CFI, suggesting that CFI is not appropriate for those patients. In a pooled analysis of CAIRO 3 and AIO 0207 trials, female gender, synchronous-resected metastasis and BRAF mutation were associated with a longer OS if maintenance chemotherapy is performed compared with observation. ${ }^{24}$ It must be pointed out that in our study, BRAF mutation was the strongest negative predictor for CFI in univariate and in multivariate analysis in the subgroup of patients with BRAF status determination. In regard to these and our results, it seems reasonable to recommend a maintenance chemotherapy rather than CFI in patients with BRAFmutated tumour.
Our study has several limitations. First, it is a post hoc unplanned analysis, a prospective trial comparing treatment adaptation according to prognostic factors with no adaptation, which could only demonstrate the validity of the concept. A switch to oxaliplatin and/or to anti-EGFR in the case of RAS wildtype tumour, or to other targeted therapies in the case of $B R A F$ mutant tumour according to recent results, ${ }^{25}$ could be evaluated if the signal of early progression during induction is observed, and maintenance chemotherapy as 5FU or capecitabine plus bevacizumab combination could be compared with CFI if it was a signal of short CFI. In the subgroup of patients with tumour BRAF mutation, it would be of interest to compare continuous induction chemotherapy with capecitabine plus bevacizumab chemotherapy or encorafenib plus cetuximab. Second, all the patients received irinotecan and bevacizumab treatment; thus, whether our findings could be extended to first-line oxaliplatin and/or antiEGFR-based chemotherapy remains to be demonstrated.

In conclusion, early progression may be anticipated in the case of elevated leukocytes at baseline, and no CEA decrease at first evaluation. Further study should be performed to evaluate other 
radiologic or biologic predictors. Caution should be taken before performing a CFI without maintenance treatment in patients with BRAF-mutated tumour or lack of tumour response at first evaluation. Our results would help making decisions for patients who prefer a complete CFI rather than maintenance chemotherapy. Further studies are needed in a larger number of patients to confirm these results and add eventually other prognostic factors.

\section{ACKNOWLEDGEMENTS}

The authors acknowledge all sub-investigators and the clinical staff at each hospital for their active participation and contribution to the good conduct of this study. We thank all participating patients and their families. We thank the FFCD operational team (data manager and CRAs) with Charles Fuchey, Fadil Masskouri, Marie Moreau, Caroline Choine, Florence Guiliani, Nouredine Lasmi, Guillaume Arnould, Nathan Guiet, Morgane Maury-Nègre, Hicham Fattouh, Nicolas Le Provost, Jérémie Bez and Cécile Girault. We also thank la "Ligue contre le cancer". A part of our paper has been presented as a meeting/conference abstract: ESMO 2017: T. Aparicio, J. Bennouna, K. Le Malicot, V. Boige, J. Taieb, O. Bouche, E. Francois, J-M. Phelip, C. Borel, R. Faroux, L. Dahan, J-B. Bachet, J. Egreteau, MC. Kaminsky-Forrett, J-M. Gornet, O. Cojocarasu, M. Gasmi, V. Guerin-Meyer, F. Ghiringhelli and C. Lepage. Predictive factors for early progression during induction chemotherapy and chemotherapy-free interval: analysis from PRODIGE 9 trial. Ann. Oncol. 28 (Suppl 5), 189 (2017) abstract 557P. JFHOD 2019: T. Aparicio, J. Bennouna, K. Le Malicot, V. Boige, J. Taïeb, O. Bouché, JM. Phelip, E. François, R. Faroux, L. Dahan, JB. Bachet, J. Egreteau, MC. Kaminsky, JM. Gornet, O. Cojocarasu, M. Gasmi, V. Guerin-Meyer, F. Ghiringhelli, C. Lepage and C. Borel. Facteurs prédictifs d'une progression précoce pendant chimiothérapie d'induction et pendant le premier intervalle libre de chimiothérapie (Analyse des données de l'essai PRODIGE 9. JFHOD CO83, Paris 22 mars, 2019).

\section{AUTHOR CONTRIBUTIONS}

T.A.: conception and design, provision of study patients and study materials and data interpretation and paper writing; J.B.: conception and design, provision of study patients and study materials and paper review; K.L.M.: data interpretation and paper writing; V.B.: conception and design, provision of study patients and study materials and data interpretation and paper writing; O.B.: conception and design, provision of study patients and study materials and data interpretation and paper review; J.T., J.M. P., E.F., C.B., R.F., L.D., J.B.B., J.E., M.C.K., J.M.G., O.C., M.G., V.G.M., C.L. and F.G.: provision of study patients and study materials, data interpretation and paper review. The final version of the paper has been approved by all authors.

\section{ADDITIONAL INFORMATION}

Ethics approval and consent to participate The study was done in accordance with the Declaration of Helsinki. The study was approved by the Committee for the Protection of Persons lle-de France VIII on 12/07/2011. Reminder of regulatory texts currently in force: This trial will be conducted in accordance with the New European Directive 2001/20/EC. Civil liability insurance: An insurance policy was taken out by the sponsor with SHAM under contract number 137681 (Appendix 10), in accordance with article L 1121-10 of the Public Health Code. Request for CPP and AFSSAPS authorisation: This protocol has received approval from the CPP [Comité de Protection des Personnes] (Medical Ethics Committee) Ile-de-France VIII (Boulogne A. Paré) on 12/07/2011. This protocol has been authorised by the AFSSAPS (Agence Française de Sécurité Sanitaire des Produits de Santé) (French Health Products Safety Agency) on 25/07/2011. Obtaining the patient's consent: The investigator undertakes to obtain the patient's consent for the clinical and biological studies in writing, after providing adequate information. A copy of these consent forms must be kept by the investigator for 15 years, to be presented to the governing authorities in case of an inspection. The original is given to the patient. Informing hospital managements and research agreement: Before starting the study, hospital managements will be informed by the sponsor of the investigator's interest in taking part in this trial. A research contract without additional cost will be drawn up between the study centre manager and the sponsor.

\section{Consent to publish Not applicable.}

Data availability Data supporting this publication are stored at the FFCD Data Center.

Competing interests $\operatorname{Pr}$ Aparicio reports personal grants; consultancy for BMS: payments for development of educational presentations for Ipsen Pharma Roche,
Servier, Amgen; travel grants from Ipsen Pharma, Roche, Bayer. Pr Ghiringhelli reports personal grants consultancy for Roche, AstraZeneca; payments for development of educational presentations for Roche, Servier, Amgen, Merck; MSD: travel grants from Amgen, Servier, Roche. Pr Bouché reports personal grants consultancy for Roche, Merck, Amgen; payments for development of educational presentations for Bayer, Pierre Fabre, Servier, Amgen; travel grants from Lilly, Roche, Bayer. Pr Bachet reports personal grants consultancy for Amgen, AstraZeneca, Bayer, Merck Serono, Pierre Fabre and Servier; payments for development of educational presentations for Amgen, AstraZeneca, Bayer, Merck Serono, Mundipharma, Pierre Fabre, Roche, Sanofi and Servier; travel grants from Amgen, Bayer, Merck Serono, Roche, Sanofi and Servier. Dr. Cojocarasu reports payment for board participation from Sanofi; travel grants from Amgen, Roche and Pfizer. Dr. Boige reports grants, personal fees and non-financial support from Merck Serono, Bayer, Amgen, Sanofi, Daiichi Sankyo, Novartis, Roche and Prestizia, outside the submitted work. Pr Taieb reports personal grants for consultancy for Abbvie, Amgen, Baxalta, Celgene, Lilly, Merck and Roche; payment for lectures including service on speaker's bureau for ABBVIE, Amgen, Celgene, Lilly, Merck and Roche; payments for development of educational presentations for Roche and travel grants from Roche and Merck. Pr Phelip reports personal grants for board membership for Roche, Sanofi, Lilly Merck and Amgen; consultancy for Lilly and Roche; payments for development of educational presentations for Roche, Sanofi, Lilly Merck and Amgen. Pr Phelip reports grants for his institution for board membership for Roche and Merck; payments of grants from Merck and Roche. Dr. François reports personal grants for board membership for Roche, Merck and Sanofi. Dr. Faroux reports personal grants for clinical research for Merck; payment for lectures and consultancy for Amgen, Merck and Roche; travel grants from Amgen, Celgene, Merck and Roche. Pr Lepage reports personal grants for board membership for AAA, grants from Novartis and travel grants from Ipsen pharma, Amgen and Bayer. Dr. Bennouna reports personal grants for board membership for Roche, Boehringer-Ingelheim, AstraZeneca, Servier and BMS; payment for lectures including service on speaker's bureau for Roche and AstraZeneca, and travel grants from Roche and BMS. Pr Dahan reports personal grants for clinical research for Ipsen, Lilly, MSD and Sanofi; for payment for lectures and consultancy for Amgen, Baxalta, Celgene, Lilly, Merck, Sanofi and Roche; travel grants from Celgene, Ipsen and Sanofi. No other disclosures are reported.

Funding information The study was funded by Fédération Francophone de Cancérologie Digestive (FFCD). ROCHE provided financial support for study management. The study was sponsored by "Fédération Francophone de Cancérologie Digestive" (FFCD), which was responsible for the study management for design and conduct of the study; for collection, management, analysis and interpretation of the data; for preparation, review or approval of the paper; for decision to submit the paper for publication.

Supplementary information is available for this paper at https://doi.org/10.1038/ s41416-020-0735-8.

Publisher's note Springer Nature remains neutral with regard to jurisdictional claims in published maps and institutional affiliations.

\section{REFERENCES}

1. Kopetz, S., Chang, G. J., Overman, M. J., Eng, C., Sargent, D. J., Larson, D. W. et al. Improved survival in metastatic colorectal cancer is associated with adoption of hepatic resection and improved chemotherapy. J. Clin. Oncol. 27, 3677-3683 (2009).

2. Hurwitz, H., Fehrenbacher, L., Novotny, W., Cartwright, T., Hainsworth, J., Heim, W. et al. Bevacizumab plus irinotecan, fluorouracil, and leucovorin for metastatic colorectal cancer. N. Engl. J. Med. 350, 2335-2342 (2004).

3. Phelip, J. M., Tougeron, D., Léonard, D., Benhaim, L., Desolneux, G., Dupré, A. et al. Metastatic colorectal cancer (mCRC): French intergroup clinical practice guidelines for diagnosis, treatments and follow-up (SNFGE, FFCD, GERCOR, UNICANCER, SFCD, SFED, SFRO, SFR). Dig. Liver Dis. 51, 1357-1363 (2019).

4. Tournigand, C., Cervantes, A., Figer, A., Lledo, G., Flesch, M., Buyse, M. et al. OPTIMOX1: a randomized study of FOLFOX4 or FOLFOX7 with oxaliplatin in a stop-and-Go fashion in advanced colorectal cancer-a GERCOR study. J. Clin. Oncol. 24, 394-400 (2006).

5. Chibaudel, B., Maindrault-Goebel, F., Lledo, G., Mineur, L., Andre, T., Bennamoun, M. et al. Can chemotherapy be discontinued in unresectable metastatic colorectal cancer? The GERCOR OPTIMOX2 Study. J. Clin. Oncol. 27, 5727-5733 (2009).

6. Labianca, R., Sobrero, A., Isa, L., Cortesi, E., Barni, S., Nicolella, D. et al. Intermittent versus continuous chemotherapy in advanced colorectal cancer: a randomised “GISCAD” trial. Ann. Oncol. 22, 1236-1242 (2011). 
7. Pereira, A. A., Rego, J. F., de, M., Munhoz, R. R., Hoff, P. M., Sasse, A. D. \& Riechelmann, R. P. The impact of complete chemotherapy stop on the overall survival of patients with advanced colorectal cancer in first-line setting: a metaanalysis of randomized trials. Acta Oncol. 54, 1737-1746 (2015).

8. Heinemann, V., von Weikersthal, L. F., Decker, T., Kiani, A., Vehling-Kaiser, U., AlBatran, S. E. et al. FOLFIRI plus cetuximab versus FOLFIRI plus bevacizumab as first-line treatment for patients with metastatic colorectal cancer (FIRE-3): a randomised, open-label, phase 3 trial. Lancet Oncol. 15, 1065-1075 (2014).

9. Venook, A. P., Niedzwiecki, D., Lenz, H.-J., Innocenti, F., Fruth, B., Meyerhardt, J. A. et al. Effect of first-line chemotherapy combined with cetuximab or bevacizumab on overall survival in patients with KRAS wild-type advanced or metastatic colorectal cancer: a randomized clinical trial. JAMA 317, 2392-2401 (2017).

10. Cremolini, C., Loupakis, F., Antoniotti, C., Lupi, C., Sensi, E., Lonardi, S. et al. FOLFOXIRI plus bevacizumab versus FOLFIRI plus bevacizumab as first-line treatment of patients with metastatic colorectal cancer: updated overall survival and molecular subgroup analyses of the open-label, phase 3 TRIBE study. Lancet Oncol. 16, 1306-1315 (2015).

11. Aparicio, T., Linot, B., Le Malicot, K., Bouché, O., Boige, V., François, E. et al. FOLFIRI + bevacizumab induction chemotherapy followed by bevacizumab or observation in metastatic colorectal cancer, a phase III trial (PRODIGE 9-FFCD 0802). Dig. Liver Dis. 47, 271-272 (2015).

12. Simkens, L. H. J., van Tinteren, H., May, A., ten Tije, A. J., Creemers, G. J., Loosveld, O. J. et al. Maintenance treatment with capecitabine and bevacizumab in metastatic colorectal cancer (CAIRO3): a phase 3 randomised controlled trial of the Dutch Colorectal Cancer Group. Lancet 385, 1843-1852 (2015).

13. Hegewisch-Becker, S., Graeven, U., Lerchenmüller, C. A., Killing, B., Depenbusch, R., Steffens, C. C. et al. Maintenance strategies after first-line oxaliplatin plus fluoropyrimidine plus bevacizumab for patients with metastatic colorectal cancer (AIO 0207): a randomised, non-inferiority, open-label, phase 3 trial. Lancet Oncol. 16, 1355-1369 (2015).

14. Aparicio, T., Ghiringhelli, F., Boige, V., Le Malicot, K., Taieb, J., Bouché, O. et al. Bevacizumab Maintenance versus no maintenance during chemotherapy-free intervals in metastatic colorectal cancer: a randomized phase III trial (PRODIGE 9). J. Clin. Oncol. 36, 674-681 (2018).

15. Stintzing, S., Miller-Phillips, L., Modest, D. P., Fischer von Weikersthal, L., Decker, T., Kiani, A. et al. Impact of BRAF and RAS mutations on first-line efficacy of FOLFIRI plus cetuximab versus FOLFIRI plus bevacizumab: analysis of the FIRE-3 (AIO KRK0306) study. Eur. J. Cancer 79, 50-60 (2017).

16. Aparicio, T., Lavau-Denes, S., Phelip, J. M., Maillard, E., Jouve, J. L., Gargot, D. et al. Randomized phase III trial in elderly patients comparing LV5FU2 with or without irinotecan for first-line treatment of metastatic colorectal cancer (FFCD 2001-02). Ann. Oncol. 27, 121-127 (2016).

17. Michl, M., Stintzing, S., Fischer von Weikersthal, L., Decker, T., Kiani, A., VehlingKaiser, $U$. et al. CEA response is associated with tumor response and survival in patients with KRAS exon 2 wild-type and extended RAS wild-type metastatic colorectal cancer receiving first-line FOLFIRI plus cetuximab or bevacizumab (FIRE-3 trial). Ann. Oncol. 27, 1565-1572 (2016).
18. Holch, J. W., Ricard, I., Stintzing, S., Fischer von Weikersthal, L., Decker, T., Kiani, A. et al. Relevance of baseline carcinoembryonic antigen for first-line treatment against metastatic colorectal cancer with FOLFIRI plus cetuximab or bevacizumab (FIRE-3 trial). Eur. J. Cancer 106, 115-125 (2019).

19. Garlan, F., Laurent-Puig, P., Sefrioui, D., Siauve, N., Didelot, A., Sarafan-Vasseur, N. et al. Early evaluation of circulating tumor DNA as marker of therapeutic efficacy in metastatic colorectal cancer patients (PLACOL Study). Clin. Cancer Res. 23, 5416-5425 (2017)

20. Köhne, C. H., Cunningham, D., Di Costanzo, F., Glimelius, B., Blijham, G., Aranda, E. et al. Clinical determinants of survival in patients with 5 -fluorouracil-based treatment for metastatic colorectal cancer: results of a multivariate analysis of 3825 patients. Ann. Oncol. 13, 308-317 (2002).

21. Dohan, A., Gallix, B., Guiu, B., Le Malicot, K., Reinhold, C., Soyer, P. et al. Early evaluation using a radiomic signature of unresectable hepatic metastases to predict outcome in patients with colorectal cancer treated with FOLFIRI and bevacizumab. Gut. https://doi.org/10.1136/gutjnl-2018-316407 (2019).

22. Guinney, J., Dienstmann, R., Wang, X., de Reyniès, A., Schlicker, A., Soneson, C. et al. The consensus molecular subtypes of colorectal cancer. Nat. Med. 21, 1350-1356 (2015)

23. Adams, R. A., Meade, A. M., Seymour, M. T., Wilson, R. H., Madi, A., Fisher, D. et al. Intermittent versus continuous oxaliplatin and fluoropyrimidine combination chemotherapy for first-line treatment of advanced colorectal cancer: results of the randomised phase 3 MRC COIN trial. Lancet Oncol. 12, 642-653 (2011).

24. Goey, K. K. H., Elias, S. G., Hinke, A., van Oijen, M. G. H., Punt, C. J. A., HegewischBecker, S. et al. Clinicopathological factors influencing outcome in metastatic colorectal cancer patients treated with fluoropyrimidine and bevacizumab maintenance treatment vs observation: an individual patient data meta-analysis of two phase 3 trials. Br. J. Cancer 117, 1768-1776 (2017).

25. Kopetz, S., Grothey, A., Yaeger, R., Van Cutsem, E., Desai, J., Yoshino, T. et al. Encorafenib, binimetinib, and cetuximab in BRAF V600E-mutated colorectal cancer. N. Engl. J. Med. 381, 1632-1643 (2019).

Open Access This article is licensed under a Creative Commons Attribution 4.0 International License, which permits use, sharing, adaptation, distribution and reproduction in any medium or format, as long as you give appropriate credit to the original author(s) and the source, provide a link to the Creative Commons license, and indicate if changes were made. The images or other third party material in this article are included in the article's Creative Commons license, unless indicated otherwise in a credit line to the material. If material is not included in the article's Creative Commons license and your intended use is not permitted by statutory regulation or exceeds the permitted use, you will need to obtain permission directly from the copyright holder. To view a copy of this license, visit http://creativecommons. org/licenses/by/4.0/.

(c) The Author(s) 2020 